\title{
Centrifuge modelling of tunnelling beneath axially loaded displacement and non-displacement piles in sand
}

\author{
Andrea Franza ${ }^{1}$ and Alec M. Marshall, Ph.D. ${ }^{2}$ \\ ${ }^{1}$ Department of Civil Engineering, Faculty of Engineering, University of Nottingham, University \\ Park, Nottingham, NG7 2RD, United Kingdom; e-mail: andreafranza@gmail.com \\ ${ }^{2}$ Department of Civil Engineering, Faculty of Engineering, University of Nottingham, University \\ Park, Nottingham, NG7 2RD, United Kingdom; e-mail: alec.marshall@ nottingham.ac.uk
}

\begin{abstract}
Tunnelling under piled structures is becoming more common in urban areas. However, there is limited guidance available for the prediction of settlements and the loss of bearing capacity of existing piles due to tunnel excavation. This paper aims to provide an improved understanding of the response to tunnelling of axially loaded displacement and non-displacement piles. Data are provided from a series of geotechnical centrifuge tests of tunnel excavation beneath single piles in dry silica sand. The tests evaluate induced settlements of the piles at varying levels of initial safety factor (i.e. the ratio between initial bearing capacity and applied load). Furthermore, a previously published analytical approach, based on cavity expansion theory, is used to investigate the variation of the residual safety factor at constant pile load with tunnel volume loss. The outcomes of both centrifuge and analytical investigations illustrate the importance of pile installation method and initial safety factor and improve understanding of tunnel-pile interaction mechanisms.
\end{abstract}

\section{INTRODUCTION}

The development of urban areas has resulted in an increased demand for underground construction. This often involves the excavation of new tunnels which affect nearby existing infrastructure and structures. The construction of new tunnels in the proximity of deep foundations raises concerns related to pile failure and associated structural damage (in both the superstructures and the foundation). Therefore, engineers need tools to assist with decisions related to tunnel route/depth and provision of preventative actions, such as compensation grouting.

In recent years, a number of authors have investigated the problem of tunnelling adjacent to and beneath piles and pile groups. This problem has been analysed with field trials (Kaalberg et al. 2005), experimentally (Jacobsz et al. 2004; Marshall \& Mair 2011), analytically (Zhang et al. 2011; Marshall 2012; Marshall \& Haji 2015) and numerically (Basile 2014, Soomro et al. 
2015). Recent research has considered the response of piled structures to tunnelling (Franza \& Marshall 2016, Franza et al. 2016). In general, a good understanding exists of the basic tunnelsingle pile and tunnel-pile group interaction mechanisms and pile failure, which depend on the load redistribution between the base and shaft. The response to tunnelling of displacement and non-displacement piles and the importance of the relative tunnel-pile tip location have been considered. Recent studies have also provided evidence of the importance of pile loading condition (Zhang et al. 2011; Dias \& Bezuijen 2015). This should impact previously proposed relationships between pile and greenfield surface settlements, which is described as a function of the pile tip location with respect to the tunnel: piles with their tips within the area of major settlements above the tunnel settle more than the surface greenfield settlement trough; piles outside this area settle less than surface greenfield levels.

Regarding the pile failure mechanism, it has been illustrated that, because of tunnelling, there is a decrease of bearing capacity $(\Delta Q<0$, where $Q$ is the maximum bearing load). If we assume a constant pile load ( $P=$ constant), pile failure occurs when the pile bearing capacity reaches the value of the applied load $(Q \rightarrow P)$. At this stage, because of the equilibrium condition, the pile bearing capacity has to be equal to the applied load $(Q=P)$ and any further decrease of bearing capacity caused by an increment of tunnel volume loss has to be compensated by pile settlements. If the pile settlement is not able to satisfy the equilibrium condition $(Q<P)$, the pile does not stabilise and potentially large settlements occur.

This paper presents data collected from a series of centrifuge tests of tunnel excavation beneath single piles. Tunnelling beneath piles is a critical scenario because it results in differential pile settlements amongst a transverse row of piles within a foundation system. This research aims to provide an improved understanding of the response to tunnelling of axially loaded displacement and non-displacement piles at varying levels of initial safety factor (ratio between pre-tunnelling bearing capacity and applied service loads). Additionally, an analytical method based on cavity expansion theory is used to model the experiment scenarios and to investigate the reduction of pile bearing capacity with volume loss.

\section{CENTRIFUGE EQUIPMENT AND OVERVIEW OF EXPERIMENTS}

This section provides a description of the experimental equipment and the test procedure. A $1 / 60^{\text {th }}$ scale model was tested at $60 \mathrm{~g}$ (i.e. 60 times gravitational acceleration) in the University of Nottingham geotechnical centrifuge. The centrifuge creates an increased acceleration field, thereby increasing the self-weight of materials and replicating the stresses (and soil behaviour) of a full-scale prototype 60 times larger than the model. The experimental package is illustrated in Figure 1. The results from 12 experiments are presented: 1 greenfield tunnelling; 3 pile loading tests; and 8 tunnel-single pile interaction tests. Tests are labelled according to installation method ( $\mathrm{N}=$ non-displacement, $\mathrm{D}=$ displacement), pile position (see Figure 1), and initial safety factor (for instance N2SF1.5 represents a non-displacement pile located in position 2 with an initial safety factor of 1.5). In this paper, data from piles in positions 2 (offset $=75 \mathrm{~mm}$ ) and 3 (offset $=$ 
$150 \mathrm{~mm}$ ) are presented; the piles were located at the centre of the container with respect to the longitudinal tunnel direction. Note that only the pile in position 2 has its tip located within the influence zones defined by Jacobsz et al. (2004) (Figure 1b) where large pile settlements may be induced by tunnelling. The repeatability of results was verified by repeating the pile loading test three times with the same configuration. In the following, both the model dimensions and results are reported in model scale.

a)

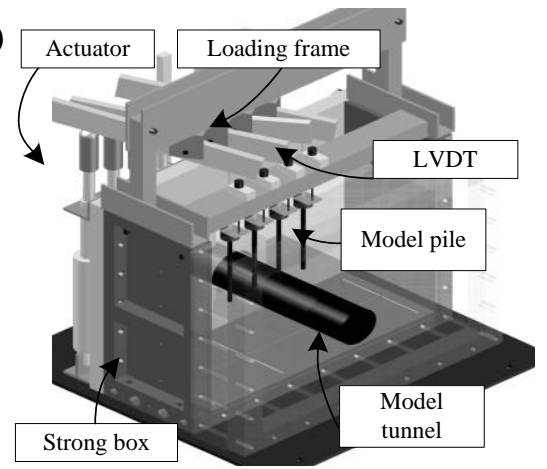

b)

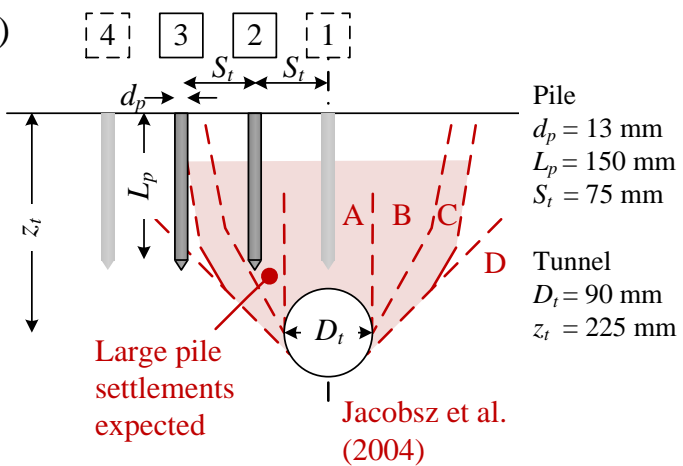

Figure 1. a) Experimental equipment; b) layout in the transverse direction.

The experimental package consists of a $90 \mathrm{~mm}$ diameter plane strain model tunnel buried in a fine grained dry silica sand, known as Leighton Buzzard Fraction E and commonly used for centrifuge testing in the UK. The tunnel was buried at $225 \mathrm{~mm}$ depth (to tunnel axis). The sand was placed by air pluviation to achieve a relative density, $I_{d}$, of $30 \%$ according to the preparation methodology described by Franza \& Marshall (2016). The tunnel ground loss is simulated using a tunnel volume control system. The model tunnel is an eccentric cylinder with enlarged ends covered by a sealed latex membrane filled with water. The tunnel volume control system is composted by a constant-head standpipe, a solenoid valve, a linear actuator, a waterfilled sealed cylinder and an LVDT. To model tunnel ground loss, the water is extracted in-flight from the tunnel and the extracted volume is related to the tunnel volume loss, $V_{l, t}$ (ratio between the volume of the ground loss per unit length of tunnel and the notional area of the tunnel cross section). The excavation is modelled by incrementing $V_{l, t}$ up to $10 \%$. Note that the tunnel membrane is fully-flexible; the structural lining is not modelled and the ground movements are due to equilibrium between the water and soil. Furthermore, the tunnel longitudinal advancement is not modelled and $V_{l, t}$ is an average value across the model tunnel. During the greenfield test, two digital cameras were used to take pictures of the soil at the front Perspex wall at each $V_{l, t}$ increment; subsurface ground movements were then measured with geoPIV (White et al., 2003).

In the case of piles, a versatile load-control system and a real-time interface, developed to study soil-structure interaction through real-time load-controlled coupling of numerical and centrifuge modelling, was used (Franza et al. 2016). The equipment can apply user-defined pile head vertical load demands in-flight. The experiments included the following components: a single pile with a fully rough interface (obtained by bonding sand to a $12 \mathrm{~mm}$ diameter 
aluminium alloy round bar, giving a final diameter, $d_{p}$, of $13 \mathrm{~mm}$ ); an in-line load cell used to measure the pile head load, P; a Linear Variable Differential Transformer (LVDT) used to measure the pile settlements $U$; a loading system able to drive the pile or to apply a user-defined load, $P$, at the pile head through a ball screw actuator and a lever system. The experimental setup allowed for high-frequency data acquisition of pile load and settlement during the tests (approximately every $40 \mathrm{~ms}$ ).

The procedure for tunnel-pile interaction tests can be summarised as follows. [1] After sand pouring, the pile was installed prior to spin up (at $1 \mathrm{~g}$ ) by jacking to the final embedment depth $L_{p}$ for non-displacement pile tests and $L_{p}-2 d_{p}$ for displacement pile tests (where the pile was driven $2 d_{p}$ in-flight). [2] The model was spun-up to $60 \mathrm{~g}$. [3a] For displacement pile tests, the pile was jacked in-flight a distance of $2 d_{p}$ and, subsequently, the pile head load was reduced to the service value $P$; [3b] for non-displacement pile tests the service load $P$ was directly applied to the pile. The value of the applied service load depended on the specified initial safety factor $\left(P=Q_{0} / S F_{0}\right.$, where $Q_{0}$ is the pre-tunnelling ultimate pile bearing capacity and $S F_{0}$ is the initial safety factor). [4] Incremental tunnel volume losses were induced and the pile settlement was measured with the LVDT. The pile load was maintained constant during the entire tunnelling process. During pile loading tests, after steps 1 and 2, the pile was jacked while pile head reaction force and settlement were measured.

The centrifuge model represents several approximations to reality. For displacement piles, the in-flight model pile jacking allows the creation of a realistic stress profile within the ground compared to the field installation of driven or jacked piles. For non-displacement piles, there is some degree of soil disturbance induced by the jacking process at $1 \mathrm{~g}$ which tends to densify the soil rather than allowing the stress relief that would happen in the real case. However, the intention of this work is to compare the tunnel-pile interaction accounting for the main difference between displacement and non-displacement piles; that is the different distribution of pile load between the pile shaft and base. Non-displacement piles withstand the pile service load mainly through shaft friction since the displacements needed to mobilise base capacity do not occur. Displacement piles have their base capacity partially mobilised by the installation process, with residual pressures locked in at the base and negative shaft friction along the shaft. The adopted centrifuge testing procedure is able to capture these important differences. This paper does not aim to investigate the differences occurring from jacking or driving piles.

\section{CAVITY EXPANSION/CONTRACTION ANALYSIS METHOD}

Cavity expansion theory has been applied to the analysis of tunnels and underground excavations. In this paper, the analytical method by Marshall and Haji (2015) is adopted to study the reduction of bearing capacity of single piles due to tunnelling. The formulation, which was applied to displacement piles in the paper, was extended to allow investigation of nondisplacement piles. 
The analytical method consists of the following 4 stages. [a] For displacement piles, where pile installation has a remarkable effect on the ground, it is necessary to replicate the pile installation. A spherical cavity expansion analysis is used to evaluate the limiting cavity pressure and the change in ground stress around the pile due to its installation; furthermore, a procedure to account for the effect of pile installation on soil stiffness is included. For non-displacement piles, the end-bearing capacity is neglected, which is a conservative assumption. [b] The end-bearing and shaft capacity of the pile is evaluated following the methods of Randolph et al. (1994) and Fleming et al. (2009). [c] A cylindrical cavity contraction analysis is used to evaluate the effect of tunnel volume loss (cavity contraction) on the stresses within the ground. [d] The reduction in pile end-bearing and shaft capacity is evaluated based on the altered stress conditions within the ground (due to [c]) at the tip and the shaft of the pile. This method does not provide information on tunnelling-induced displacements.

A pile capacity reduction factor $R_{Q, S}$ which accounts for the effect of the tunnel contraction on both pile end-bearing and shaft capacities was defined by Marshall and Haji (2015) as

$$
R_{Q, S}\left[V_{l, t}\right]=\frac{Q_{V l t}}{Q_{0}}=\frac{q_{b, V l t} d_{p}+4 \bar{\tau}_{S, V l t} L_{p}}{q_{b, 0} d_{p}+4 \bar{\tau}_{S, 0} L_{p}}
$$

where $Q$ is the pile bearing capacity, $q_{b}$ is the end-bearing capacity pressure of the pile; $\bar{\tau}_{S, V l t}$ is the average shear stress along the pile shaft, and the subscripts 0 and $V_{l t}$ indicate the initial and post tunnel volume loss values, respectively. The value of $R_{Q, s}$ at pile failure was investigated and compared against centrifuge test data for tunnelling beneath jacked piles in dense sand. The authors suggested that $R_{Q, S}=0.85$ corresponds conservatively to a critical value of tunnel volume loss, $V_{l, t}^{f}$, associate with pile failure and potentially large displacements. However, this approach neglects the importance of the pile working rate (i.e. the initial pile safety factor) and would lead to the same value of $V_{l, t}^{f}$ in the case of different service loads, $P$.

If the definition of initial safety factor, $S F_{0}=Q_{0} / P$, and residual safety factor after ground loss, $S F_{V l t}=Q_{V l t} / P$, are introduced as the ratio between the pile bearing capacity, $Q$, and the service load, $P$, the residual safety factor can be computed as

$$
S F_{V l t}=R_{Q, S} \times S F_{0}
$$

By definition, pile failure due to the critical volume loss is associated with $S F_{V l t}=1$. Therefore, considering Equation (2), the reduction factor at failure, $R_{Q, S}^{f}$, is equal to the inverse of $S F_{0}$. In a subsequent section, the cavity expansion/contraction method is used to analyse centrifuge experiment data to provide insights into the tunnel-pile interaction mechanism and the loss of bearing capacity due to tunnel excavation. 


\section{RESULTS}

To investigate the effects of varying initial safety factor, it was necessary to measure the bearing capacity of the model piles, $Q_{0}$. For non-displacement piles, it was assumed that $Q_{0}$ was equal to the load required to push a pile by $10 \%$ of the pile diameter. For displacement piles, $Q_{0}$ was set to the maximum installation force measured at the end of the jacking process (end of stage [3a]). It is important to note that $Q_{0}$ could be measured during each test involving displacement piles whereas the assessment of $Q_{0}$ for non-displacement piles required the additional pile loading centrifuge tests. Figure $2 \mathrm{a}$ and $\mathrm{b}$ display, respectively, the load-settlement $\left(u_{z}\right)$ curve for nondisplacement and displacement piles.
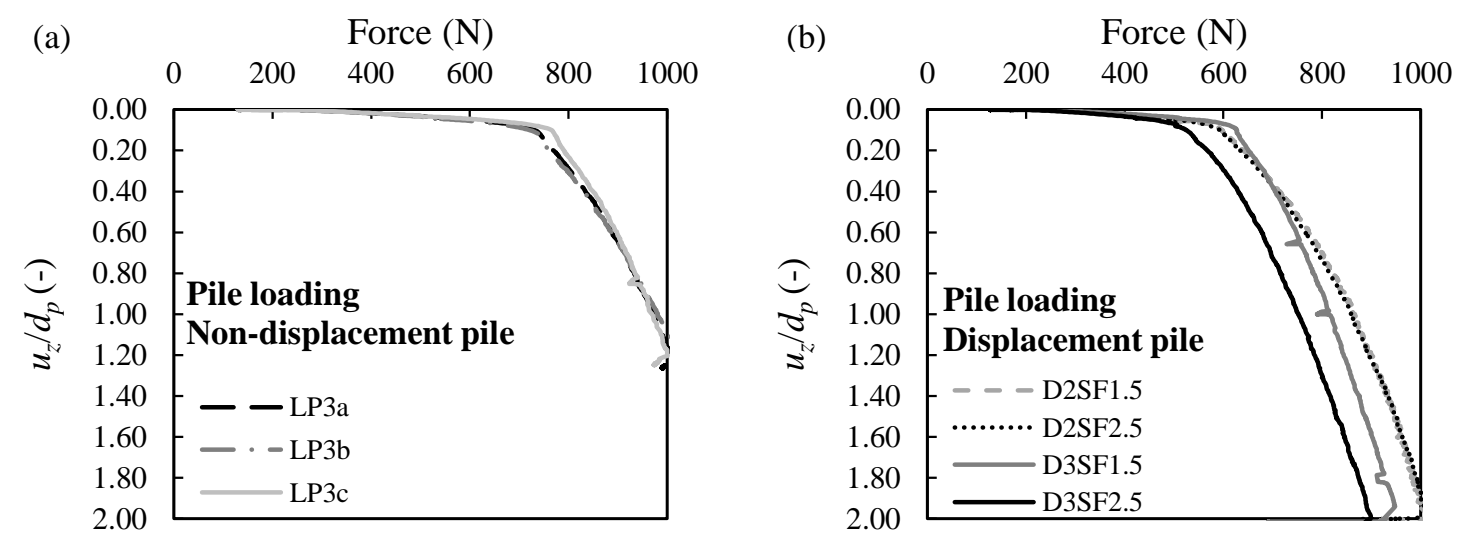

Figure 2. Load vs normalised settlement curves for (a) non-displacement piles and (b) displacement piles.

During the centrifuge tests, an average $Q_{0}=740 \mathrm{~N}$ was measured for the nondisplacement piles at $10 \% d_{p}$, whereas $Q_{0}=1000 \mathrm{~N}$ was assumed for displacement piles. The variation of ultimate load of the displacement piles can in part be attributed to the different pile positions, since increased horizontal stresses near the tunnel axis depth due to water pressure distribution in the tunnel ( $K=1$, as opposed to $K \approx 0.5$ if the model tunnel was not present, where $K$ is the ratio of horizontal to vertical stresses) would affect pile capacity.

In Figure 3, the results of the centrifuge tests are compared with those from the cavity expansion/contraction analyses. The normalised pile settlements, $u_{z} / d_{p}$, due to ground loss are shown in Figure 3a and b. Data are presented up to a tunnel volume loss of 5\%, which is higher than might be expected in practice, to enable an adequate comparison with the analytical results. The variation of pile capacity reduction factor, $R_{Q, S}$, and the residual safety factor $S F_{V l t}=$ $R_{Q, S} \times S F_{0}$ with $V_{l, t}$ are displayed in Figure $3 \mathrm{c}$, d, e and $\mathrm{f}$.

Regarding pile settlements, for practical purposes, as suggested by Jacobsz et al. (2004), an arbitrary prototype settlement value of $20 \mathrm{~mm}$ may define the threshold of "large" settlements, which corresponds to $0.026 d_{p}$ at model scale. Furthermore, the value of $0.10 d_{p}$ is used in this paper to refer to "very large" settlements, which relate to performance-based 
requirements of structures. In these figures, greenfield displacements at the locations of the pile head and tip are also plotted because they are often used as a reference for tunnel-pile interaction analyses.

The following observations can be drawn from Figure $3 a$ and $b$ :

- Pile initial safety factor, $S F_{0}$, has a great influence on the tunnelling-induced settlements. The higher the value of $S F_{0}$, the lower the pile displacement for both displacement and nondisplacement piles.

- For a given $S F_{0}, V_{l, t}$ at failure is higher for non-displacement piles than for displacement piles. Only piles in position 2 with $S F_{0}=1.5$ underwent failure, with the displacement and non-displacement piles displaying a sharp increase in rate of displacement after $1 \%$ and $4 \%$ volume loss, respectively. Note that the failure of the piles is not as brittle as that described by Marshall \& Mair (2011); this may be due to the contractive soil behaviour in these tests due to its low relative density $\left(I_{d}=30 \%\right)$.

- The rate of displacement increases with volume loss for piles in position 2, whereas it decreases for piles in position 3.

- Pile settlements are within the range defined by the pile head and tip displacements at low volume losses $\left(V_{l, t}<1 \%\right)$, whereas pile settlements are larger than greenfield movements at higher volume losses. In particular, it is interesting to note that, at low volume losses $\left(V_{l, t}<1 \%\right)$, non-displacement pile settlements are slightly greater than and close to surface greenfield settlements in positions 2 and 3, respectively, as suggested by previous researchers. On the other hand, the settlements of displacement piles in both positions 2 and 3 with $S F=2.5$ follow the trends of greenfield ground movements at the pile tip, settling less than the greenfield surface values. This outcome is due to the displacement piles being end-bearing and following the tunnelling-induced soil movements at the pile tip. However, displacement piles with $S F=1.5$ may settle as much as or more than non-displacement piles. Therefore, in the context of risk assessment at low volume losses $\left(V_{l, t}<1 \%\right)$, the settlement magnitude of displacement piles located within the tunnel influence zone may decrease notably with an increase in pile safety factor.

Pile capacity reduction factor $\left(R_{Q, S}\right)$ and the residual safety factor $\left(S F_{V l t}\right)$ are also presented in Figure 3. Note that the $\mathrm{x}$-axis scale is the same for all charts to allow for the comparison of analytical and experimental data. As previously mentioned, the value of $R_{Q, S}$ does not account for $S F$. According to the trend of $R_{Q, S}$, the capacity reduction is sharp for displacement piles (tending to an asymptotic value) and gradual for non-displacement piles. This is due to the fact that displacement piles are end-bearing (the pile tip is more affected by the tunnelling-induced stress relief because it is closer to the tunnel than most of the area of the shaft) and that an increased soil stiffness is used in the analysis to account for the effect of pile driving on the stiffness of the soil (therefore, the stress relief due to tunnelling is higher for a given volume loss). This means that the difference between displacement and non-displacement piles is higher for piles closest to the tunnel. Comparing the $R_{Q, S}$ calculations to the centrifuge 
data, the criteria of $R_{Q, S}>0.85$ defined by Marshall and Haji (2015) would appear to be overly conservative, regardless of $S F$. The prediction would be realistic only for the displacement pile in position 2 with $S F=1.5$.

Comparing the centrifuge data to the residual safety factor $S F_{V l t}=R_{Q, S} \times S F_{0}$ (Figure 3a and $\mathrm{b}$ versus Figure $3 \mathrm{e}$ and $\mathrm{f}$ ) illustrates that: [i] $R_{Q, S} \times S F_{0}$ allows for a conservative and efficient prediction of the failure volume loss in the case of $S F=1.5$, and [ii] it accurately predicts that pile failure in position 2 is only expected in the case of high volume loss when $S F=2.5$.

The results shown in Figure 3 provide important insights into tunnel-pile interaction. Overall, the risk of failure of piles located within the tunnel influence area is low for nondisplacement piles and needs assessment for displacement piles if $V_{l, t}>0.5 \%$. The magnitude of tunnelling-induced settlements of piles depends considerably on the initial safety factor.

\section{DISCUSSION ON SETTLEMENTS AND PILE CAPACITY LOSS}

This section discusses the concept of pile failure and the criteria relating pile capacity loss with tunnelling-induced settlements. In loading tests, the state of pile failure is often identified as the point when the increase of pile settlements for a given increment of load (i.e. the first derivative) has a sharp rise. Similarly, tunnelling-induced pile failure should be described as the moment when the rate of increase of the pile settlement with tunnel volume loss shows a significant increase.

In the literature, tunnelling-induced settlements have been associated with capacity loss and failure. For instance, Dias \& Bezuijen (2015) related pile failure to a settlement criteria of $10 \% d_{p}$, whereas Soomro et al. (2015) introduced the apparent loss of pile capacity defined as the pile head load that would induce, according to a pre-tunnelling pile load-settlement curve, a foundation settlement equal to the tunnelling-induced displacement. However, this approach may mislead the tunnel-pile interaction analysis because it neglects the fact that tunnelling-induced pile settlements are due to both the greenfield soil movements and soil stiffness/strength degradation (only the latter component is associated with loss of bearing capacity). For instance, if the greenfield settlement field is approximately constant along the pile length and the tunneling-induced soil stiffness/strength degradation is negligible, the change in pile capacity $\Delta \mathrm{Q}$ $\approx 0$, whereas pile settlements would be equal to the greenfield value. Therefore, it is not possible to correlate pile capacity loss with pile settlements when neglecting the amount of pile settlement that is due to the pile simply following the surrounding settling soil.

To understand the main difference between pile capacity in the tunnelling scenario and the loading test, it is necessary to consider the greenfield displacement field. During a loading test, the pile displaces with respect to a stationary soil (i.e. greenfield soil movements are null). On the other hand, tunnel excavation results in greenfield soil movements associated with soil shear strains and a reduction of ground stresses. If a pile is located near the tunnel, [i] the pile settles with the surrounding soil while the pile axial stiffness acts to average the soil settlement 
distribution along its length (resulting in relative pile-soil displacements and further soil shear strains). Furthermore, [ii] the pile undergoes additional settlement with respect to the surrounding soil because of soil stress relief due to tunnel volume loss, which induces a reduction of $Q$, and soil stiffness degradation due to soil shear strains (which are induced by both greenfield tunnelling and relative soil-pile movements).
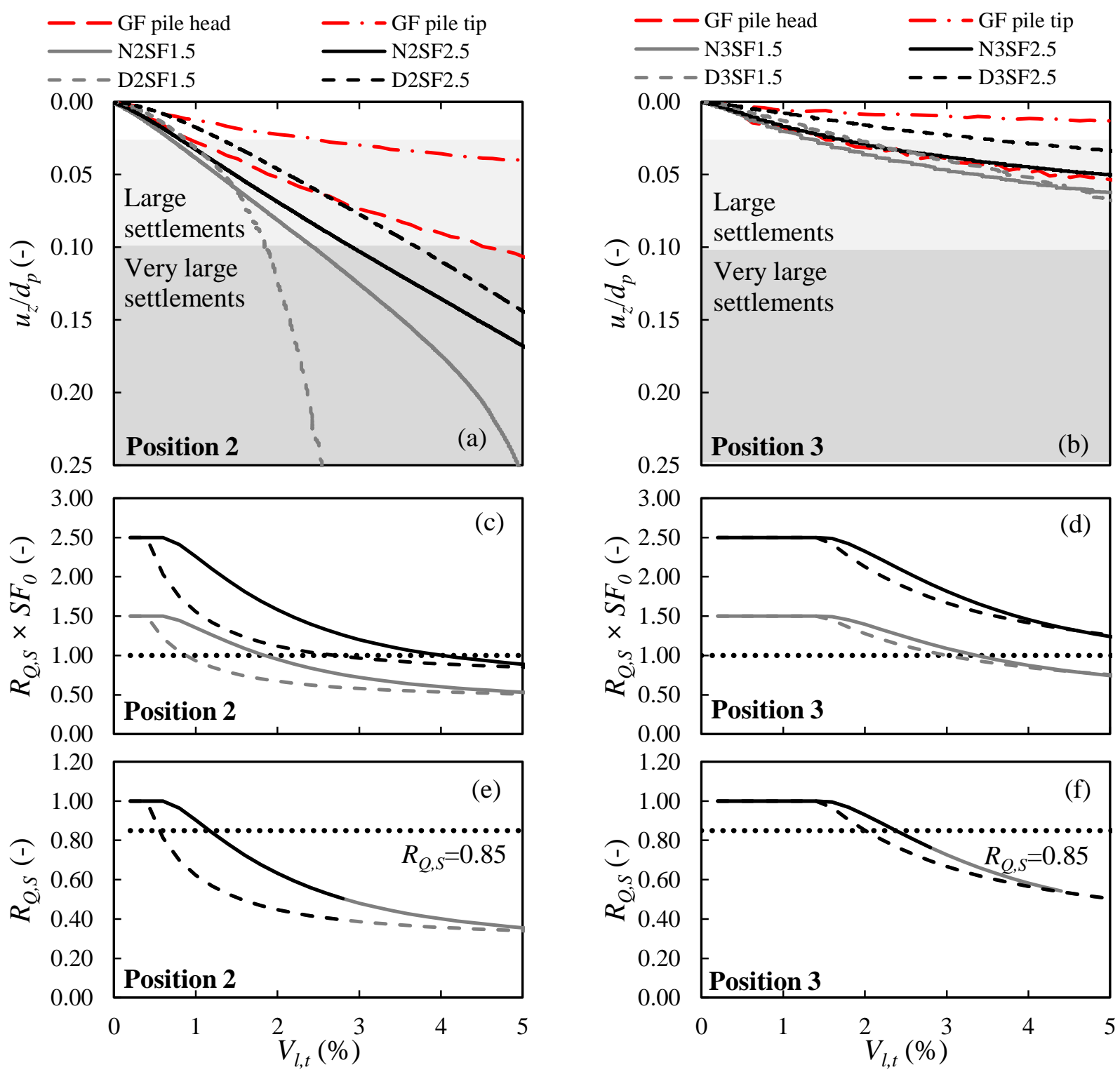

Figure 3. (a) (b) Normalised settlement vs $V_{l, t}$; (c) (d) $R_{Q, S} \times S F_{0}$ vs $V_{l, t}$; (e) (f) $R_{Q, S}$ vs $V_{l, t}$.

The use of simple criteria based on the tunnelling-induced settlements to describe pile capacity loss is questionable. Pile capacity should be evaluated with tools that consider stress relief due to tunnelling (such as the cavity expansion/contraction method adopted in this paper), which is probably the main cause of the reduction of ultimate bearing capacity. On the other hand, pile settlements do provide useful guidance to assess the potential for damage to a 
superstructure. In this framework, an ultimate tunnelling-induced pile settlement of $10 \% d_{p}$ could be assumed.

Finally, it should be noted that the requirements of the superstructure ultimate limit state may specify a residual pile safety factor after tunnel excavation greater than unity (i.e. $S F_{V l t}=$ $\left.Q_{V l t} / P>1\right)$ to withstand design extreme events inducing a load greater than the service load $P$, as in the case of bridges. Therefore, evaluation of the acceptable tunnel volume loss should be carried out considering both settlement tolerances, to guarantee serviceability of the superstructure, and residual pile safety factor, to satisfy the requests of the ultimate limit state. Definition of the acceptable tunnel ground loss level depends on the scenario and superstructure being studied; hence the most restrictive condition cannot be defined prior to conducting a risk assessment.

\section{CONCLUSIONS}

This paper combined results from centrifuge and analytical approaches to provide insights into the initiation of pile failure due to tunnel volume loss in sands. The outcomes illustrated the importance of pile installation method and initial safety factor in sandy soils, which affect both the tunneling-induced settlements of the pile and the failure process. Large pile settlements should be expected for both non-displacement and displacement piles when the pile tip is located within previously defined tunnel influence zones. Results highlighted that pile failure is a critical aspect for displacement piles in sands with relatively low initial safety factors. On the other hand, for a given initial safety factor, non-displacement pile failure is expected at a higher value of volume loss than for displacement piles. The applicability of these results may be limited to the case of loose uniform sands; future studies will consider the effects of soil density of cohesionless soils, layered soil profiles, and cohesive ground conditions. Results were based on tests in which pile loads were maintained constant during the entire tunnelling process. Further work is planned to study the effects of load re-distribution among piles due to the action of a superstructure.

\section{ACKNOWLEDGEMENTS}

The authors would like to thank the Engineering and Physical Sciences Research Council (EPSRC) for financial support under the Grant reference number EP/K023020/1.

\section{REFERENCES}

Basile, F. (2014). "Effects of tunnelling on pile foundations." Soils Found., 54(3), 280-295.

Dias, T. G. S. and Bezuijen, A. (2015). "Data Analysis of Pile Tunnel Interaction." J. Geotech. Geoenviron. Eng., 141(12), 04015051.

Fleming, K., Weltman, A., Randolph, M. F. and Elson, W. (2009). Piling Engineering, Third Edition. Taylor \& Francis. 
Franza, A., Idinyang, S., Heron, C. M. and Marshall, A. M (2016). Development of a coupled centrifuge-numerical model to study soil-structure interaction problems. Proc., $3^{\text {rd }}$ Eur. Conf. on Phys. Model. Geotech (Eurofuge 2016), Nantes, France, 135-140.

Franza, A. and Marshall, A. M. (2016). "Centrifuge modelling of piled structure response to tunnelling." Proc., $3^{\text {rd }}$ Eur. Conf. on Phys. Model. Geotech (Eurofuge 2016), Nantes, France, 313-318.

Jacobsz, S. W., Standing, J. R., Mair, R. J., Hagiwara, T. and Sugiyama, T. (2004). "Centrifuge modelling of tunnelling near driven piles." Soils Found., 44(1), 49-56.

Kaalberg, F. J., Teunissen, E. A. H., van Tol, A. F. and Bosch, J. W. (2005). "Dutch research on the impact of shield tunnelling on pile foundations." Proc., $5^{\text {th }}$ Int. Symp. Geotech. Aspects Undergr. Constr. Soft Ground. Amsterdam, the Netherlands, 123-131.

Marshall, A. M. and Mair, R. (2011). "Tunneling beneath driven or jacked end-bearing piles in sand." Can. Geotech. J., 48(12), 1757-1771.

Marshall, A. M. (2012). "Tunnel-pile interaction analysis using cavity expansion methods." $J$. Geotech. Geoenviron. Eng., 138(10), 1237-1246.

Marshall, A. M. and Haji, T. (2015). "An analytical study of tunnel-pile interaction." Tunn. Undergr. Space Technol., 45, 43-51.

Randolph, M. F., Dolwin, J. and Beck, R. (1994). "Design of driven piles in sand." Géotechnique, 44(3), 427-448.

Soomro, M. A., Hong, Y., Ng, C. W. W., Lu, H. and Peng, S. (2015). "Load transfer mechanism in pile group due to single tunnel advancement in stiff clay." Tunn. Undergr. Space Technol., 45, 63-72.

White, D., Take, W. and Bolton, M. (2003). "Soil deformation measurement using particle image velocimetry (PIV) and photogrammetry". Géotechnique, 53(7), 619-631.

Zhang, R., Zheng, J., Pu, H. and Zhang, L. (2011). "Analysis of excavation-induced responses of loaded pile foundations considering unloading effect." Tunn. Undergr. Space Technol., 26(2), 320-335. 